\title{
Exome capture sequencing reveals new insights into hepatitis B virus-induced hepatocellular carcinoma at the early stage of tumorigenesis
}

\author{
YONG CHEN $^{1,2}$, LIJUAN WANG ${ }^{1}$, HEXIANG XU $^{1}$, XINGXIANG LIU $^{1}$ and YINGREN ZHAO ${ }^{2}$ \\ ${ }^{1}$ Institute of Liver Diseases, Huai'an Fourth People's Hospital, Huai'an, Jiangsu 223002; ${ }^{2}$ Department of Infectious Diseases, \\ The First Affiliated Hospital of the Medical College of Xi'an Jiaotong University, Xi'an, Shaanxi 710061, P.R. China
}

Received May 23, 2013; Accepted July 15, 2013

DOI: $10.3892 /$ or.2013.2652

\begin{abstract}
Hepatocellular carcinoma (HCC), the most common type of liver cancer, is the third primary cause of cancer-related mortality worldwide. The molecular mechanisms underlying the initiation and formation of HCC remain obscure. In the present study, we performed exome sequencing using tumor and normal tissues from 3 hepatitis $\mathrm{B}$ virus (HBV)-positive BCLC stage A HCC patients. Bioinformatic analysis was performed to find candidate protein-altering somatic mutations. Eighty damaging mutations were validated and 59 genes were reported to be mutated in HBV-related HCCs for the first time here. Further analysis using whole genome sequencing (WGS) data of $88 \mathrm{HBV}$-related HCC patients from the European Genome-phenome Archive database showed that mutations in 33 of the 59 genes were also detected in other samples. Variants of two newly found genes, ZNF717 and PARP4, were detected in more than $10 \%$ of the WGS samples. Several other genes, such as FLNA and CNTN2, are also noteworthy. Thus, the exome sequencing analysis of three BCLC stage A patients provides new insights into the molecular events governing the early steps of $\mathrm{HBV}$-induced $\mathrm{HCC}$ tumorigenesis.
\end{abstract}

\section{Introduction}

Hepatocellular carcinoma ( $\mathrm{HCC}$ ), the most common type of liver cancer, is the third primary cause of cancer mortality

Correspondence to: Professor Yong Chen, Institute of Liver Diseases, Huai'an Fourth People's Hospital, 128 Yan'an East Road, Huai'an, Jiangsu 223002, P.R. China

E-mail: xxchenguo@163.com

Professor Yingren Zhao, Department of Infectious Diseases, The First Affiliated Hospital of the Medical College of Xi'an Jiaotong University, 277 Yanta West Road, Xi'an, Shaanxi 710061, P.R. China

E-mail: zhaoyingren@sohu.com

Key words: hepatocellular carcinoma, hepatitis B virus, exome sequencing, somatic mutation worldwide (1). The approximately 750,000 new liver cancer cases and 700,000 deaths worldwide each year are a relatively high burden (2). Among primary liver cancer, HCC, which arises from hepatocytes, represents the major histological subtype, accounting for $70-85 \%$ of all cases worldwide (3). The common risk factors for HCC include viral hepatitis, alcohol, non-alcoholic fatty liver disease and toxin such as aflatoxin, hemochromatosis, $\alpha 1$-antitrypsin deficiency (4). Chronic hepatitis B virus (HBV) infection accounts for approximately half of all cases of HCC (1), and it is the most common etiology of $\mathrm{HCC}$ in Asian countries.

Based on the current understanding of tumorigenesis, cancer is a genetic disease that arises from a single clone of cells expanding in an unregulated manner due to genomic instability and somatically acquired mutations $(5,6)$. The pathogenesis of liver cancer is considered a multistep process. HCC may develop through a multistep process involving multiple genetic events over decades of chronic liver disease, which could facilitate the progressive accumulation of somatically genetic alterations. These newly somatic mutations, which trigger oncogenes and/or inactivate tumor-suppressor genes (TSGs), and preexisting endogenous virus- or chemicalinduced mutations may lead to liver cancer, in particular HCC.

Recently, with markedly increased throughput, next-generation sequencing (NGS) technologies provide an efficient tool to identify the somatic mutations at exome and even the whole genome level (7). Several reports involving whole-genome and/or whole-exome sequencing on human HCC samples with viral infection were recently published, and provide a catalog of somatic mutations in the cancer genome, including candidate cancer genes in HCC (8-11). Although previous studies have revealed that certain genetic alterations, such as TP53 and $\beta$-catenin mutations, occur in HCC cells, the molecular mechanisms underlying the initiation and formation of HCC remain obscure.

In the present study, with a whole exome capturing approach, we sequenced the exome of tumor and normal tissues from $3 \mathrm{HBV}$-induced early stage $\mathrm{HCC}$ patients, which was diagnosed to be in stage A of Barcelona Clinic Liver Cancer (BCLC) system. Further analysis using whole genome sequencing data of $88 \mathrm{HBV}$-related $\mathrm{HCC}$ patients from the European Genome-phenome Archive database were carried 
out to discover recurrently mutated genes. Our investigation here may provide new insights into the molecular mechanism of HBV-related HCC.

\section{Materials and methods}

Sample and DNA preparation. Three male patients aged 48-52 years with chronic hepatitis B infection were diagnosed as BCLC stage A HCC in 2011 at Huai'an Fourth People's Hospital. There was only 1 tumor nodule in each patient. The tumors were all on the right lobe of liver, with the size of $3 \times 4,2 \times 4$ and $1.5 \times 3 \mathrm{~cm}^{2}$, respectively. The matched normal tissues were obtained $\sim 5 \mathrm{~cm}$ from the cancer tissues. Written informed consent from the patient was obtained, and the study was reviewed and approved by the Ethics Committees of Huai'an Fourth People's Hospital. DNA of these tissues was extracted through traditional phenol chloroform method.

Exome capture and sequencing. Exome sequencing was performed using SureSelect Human All Exon 38Mb kit (Agilent Technologies Inc., Santa Clara, CA, USA) according to the manufacturer's protocols. The capture region is $\sim 38 \mathrm{Mb}$ and covers $1.22 \%$ of the human genome that corresponds to the consensus coding sequence (CCDS) collection of genes. Genomic DNA was randomly fragmented by sonication in to an average size of $500 \mathrm{bp}$. A pair of adaptors was ligated to each end of DNA fragments. The adaptor-ligated templates were then hybridized to the array to capture fragments in target regions. The captured fragments were amplified, purified and subjected to paired-end sequencing on the Illumina GA IIx platform (Illumina, San Diego, CA, USA). The genomic DNA library preparation, targeted sequence capturing, and massively parallel sequencing were finished by Guangzhou iGenomics Co., Ltd.

Sequence analysis. The raw reads were filtered with Fastx-tools (http://hannonlab.cshl.edu/fastx_toolkit/index.html). Low quality reads were discarded (fractions of $\mathrm{N}$ bases $\geq 10 \%$ and fractions of bases with quality less than $<50 \%$ ). Then, software BWA (version 0.5.9) (12) was used to map the paired-end reads to the human reference genome (hg19). The reference genome was downloaded from the UCSC (University of California, Santa Cruz, CA, USA) database (http://genome.ucsc.edu). After the alignment, PCR duplications were removed by the SAMtools software package (version 0.1.16) (13). Candidate somatic variants were identified with the VarScan 2 software (version 2.2.8) and filtered with default parameters (14). Function prediction for all the missense single nucleotide variations (SNVs) were carried out using PROVEAN (15) and SIFT (16).

Validation of variants. Somatic indels, nonsense and missense SNVs which were predicted to be damaging with both prediction methods, were validated by PCR and Sanger sequencing. Primers were designed with Primer Premier 5 (Premier Biosoft International, Palo Alto, CA, USA). PCR amplification was performed with $50 \mu 1$ reaction using the following procedure: $95^{\circ} \mathrm{C}$ for $2 \mathrm{~min}, 35$ cycles at $95^{\circ} \mathrm{C}$ for $15 \mathrm{sec}, 60^{\circ} \mathrm{C}$ for $20 \mathrm{sec}$ and $72^{\circ} \mathrm{C}$ for $30 \mathrm{sec}$, followed by $72^{\circ} \mathrm{C}$ for $2 \mathrm{~min}$. The PCR products were purified with E.Z.N.A. ${ }^{\circledR}$ Gel Extraction kit. Sanger sequencing was performed on an ABI 3730 DNA Analyzer. Sequence trace files were manually analyzed.

Whole genome sequence analysis. In order to examine the prevalence of the mutated genes with validated damaging variants in various stages of HCCs, we further checked their mutation frequency in $88 \mathrm{HBV}$-related HCC patients using whole genome sequencing (WGA) data downloaded from the European Genome-phenome Archive database (ftp://ftp.sra.ebi.ac.uk/). The data set was not restricted to BCLC stage A patients. Early-to-advanced stage HCCs were included. Detailed information on the patients was provided in a previous study (8) which focused on HBV integration detection. Sequence alignment and somatic variants calling were carried out using the same procedure of exome sequencing reads analysis.

\section{Results}

Three patients with chronic HBV infection were diagnosed as BCLC stage A of HCC without metastasis in 2011. To identify the somatic mutations related to the disease, we performed the exome capture with Agilent SureSelect 38Mb kit for the 3 pairs of cancer and normal tissues. The captured samples with insertion size of 300-400 bp were subjected to paired-end sequencing using Illumina GA IIx. For the 3 pairs of samples, $34.93 \mathrm{~Gb}$ clean data were obtained (Table I). A total of $20.76 \mathrm{~Gb}$ data were mapped to the target region, achieving a minimum mean depth of 40.14 (Table I). The coverage of target region for each sample was all $>95 \%$. The capture rate for each sample ranged from 52.44 to $68.66 \%$ (Table I).

All uniquely mapped sequences (target regions and adjacent regions) were used for subsequent variant detection. Using VarScan 2 with default parameters, 461, 524 and 638 somatic variants were identified for the 3 samples, respectively (Table II). According to the annotation results, a total of 266 variants were found to be protein-altering, including 16 exonic indels, 12 nonsense SNVs, 227 missense SNVs and 12 splicing site mutations (Table II). Among these indels, we found 10 mutations leading to frameshift and 6 mutations causing amino acid residue deletion or insertion (Table II).

Function prediction results for missense SNVs and splicing sites showed that 82 missense SNVs (29 in S1, 16 in S2 and 37 in S3, respectively) were predicted to be damaging by both prediction methods. These SNVs, together with the indels and nonsense mutations, were further validated with PCR and Sanger sequencing. A total of $80(74.1 \%, 80 / 108)$ variants in 78 genes were validated. The distribution pattern of these validated variants across the whole genome is shown in Fig. 1. Detailed information on these variants is listed Table III. Of the variants, $85 \%(68 / 80)$ have not been reported in the dbSNP database (version 137) before. Nineteen of the 78 genes were already reported to mutate in HCC by previous studies according to the Catalogue of Somatic Mutations in Cancer (COSMIC) database (version v64). The other 59 genes were first reported to mutate in $\mathrm{HCC}$ in this study. All the validated, mutated genes were annotated through the Kyoto Encyclopedia of Genes and Genomes (KEGG) pathway analysis. Thirty genes are involved in various pathways, such as MAPK signaling pathway, Wnt signaling pathway and cell adhesion molecules (CAMs). 
Table I. Data summary of exome sequencing.

\begin{tabular}{|c|c|c|c|c|c|c|}
\hline \multirow[b]{2}{*}{ Samples } & \multicolumn{2}{|c|}{$\mathrm{S} 1$} & \multicolumn{2}{|c|}{ S2 } & \multicolumn{2}{|c|}{ S3 } \\
\hline & Tumor & Normal & Tumor & Normal & Tumor & Normal \\
\hline Raw data $(\mathrm{Gb})$ & 4.91 & 4.32 & 7.76 & 7.64 & 7.62 & 7.96 \\
\hline Read length (bp) & 100 & 100 & 100 & 100 & 100 & 100 \\
\hline Clean data $(\mathrm{Gb})$ & 3.64 & 3.16 & 7.01 & 6.96 & 6.92 & 7.24 \\
\hline Uniquely mapped on the genome (Gb) & 3.17 & 2.76 & 6.43 & 6.23 & 6.45 & 6.57 \\
\hline Mapped on target region $(\mathrm{Gb})$ & 1.77 & 1.45 & 4.37 & 4.30 & 4.36 & 4.51 \\
\hline Capture rate (\%) & 55.98 & 52.44 & 67.99 & 68.90 & 67.66 & 68.66 \\
\hline Mean depth of target region (x) & 49.03 & 40.14 & 85.01 & 83.53 & 84.82 & 87.69 \\
\hline Coverage of target region (\%) & 95.82 & 96.17 & 99.90 & 99.90 & 99.80 & 99.80 \\
\hline
\end{tabular}

Table II. Statistics of the identified somatic variants for each sample.

\begin{tabular}{lrrr}
\hline Annotation & S1 & S2 & S3 \\
\hline Splicing & 4 & 3 & 5 \\
ncRNA_splicing & 1 & 0 & 0 \\
Downstream & 3 & 7 & 6 \\
UTR5 & 3 & 5 & 18 \\
ncRNA_exonic & 6 & 14 & 10 \\
Intergenic & 87 & 93 & 102 \\
ncRNA_UTR5 & 0 & 1 & 0 \\
Intronic & 208 & 269 & 290 \\
ncRNA_UTR3 & 0 & 0 & 1 \\
Exonic & 111 & 90 & 160 \\
UTR3 & 10 & 14 & 26 \\
Upstream & 2 & 7 & 9 \\
ncRNA_intronic & 29 & 12 & 15 \\
Frameshift insertion & 0 & 2 & 1 \\
Unknown & 2 & 1 & 3 \\
Nonframeshift insertion & 1 & 0 & 1 \\
Frameshift deletion & 1 & 0 & 6 \\
Stopgain SNV & 2 & 3 & 7 \\
Nonframeshift deletion & 2 & 2 & 0 \\
Nonsynonymous SNV & 71 & 54 & 102 \\
Synonymous SNV & 32 & 28 & 40 \\
\hline
\end{tabular}

Variants are annotated based on transcripts, i.e., one variant may be assigned as different types according to different transcripts. Therefore, overlap exists in different cells from the same column in this table.

These 80 somatic mutations would cause protein changes. Genes with these variants were defined as candidate HCC-related genes and were selected for further analysis. Whole genome sequence analysis was carried out to analyze the prevalence of the 78 mutated genes in $88 \mathrm{HBV}$-related HCC patients. For these patients, a minimum 751.49 million reads were mapped to the genome for each sample, yielding a minimum mean depth of 23.3

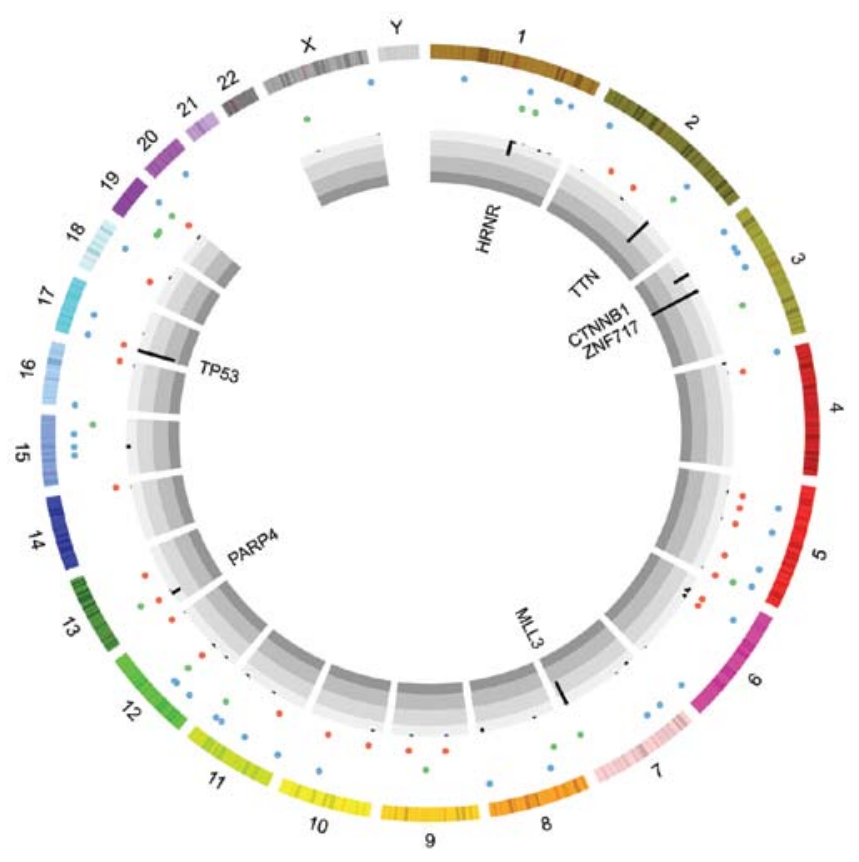

Figure 1. Distribution of validated protein-altering variants across the whole genome. Variants in S1, S2 and S3 are shown in red, green and blue dots respectively. The black bars show the mutation frequency in $88 \mathrm{HCC}$ patients for genes with validated variants. Seven genes mutated in at least 9 patients (over 10\%) are indicated. $\mathrm{HCC}$, hepatocellular carcinoma.

and a minimum coverage of $99.03 \%$ of the whole genome. Forty-seven genes were found to be mutated in at least one patient. Thirty-three of them have not previously been reported in the COSMIC database.

Genes mutated in at least 9 patients of the 88 samples $(>10 \%)$ are indicated in Fig. 1. Two of these seven genes, ZNF717 and PARP4 have not been reported in the COSMIC database before. ZNF717 showed the highest frequency as variants of this gene were found in 47 of the 88 samples. Furthermore, the missense SNV in this gene was not reported in the dbSNP database before. This SNV was also detected in another patient of the $88 \mathrm{HCC}$ samples. The variant in PARP4 was also reported for the first time. According to the KEGG database, the protein encoded by PARP4 is involved in the base excision repair pathway. The remaining 5 genes, 
Table III. Information on the validated somatic mutations.

\begin{tabular}{|c|c|c|c|c|c|c|c|c|c|c|c|}
\hline Gene & Chr & Position & Ref & Alter & Ref_aa & Alter_aa & Type & Sample & COSMIC & Num in $88^{a}$ & $\mathrm{dbSNP}$ \\
\hline$A B C C 9$ & 12 & 21954112 & $\mathrm{G}$ & A & $\mathrm{R}$ & $*$ & Nonsense & S3 & No & 2 & NA \\
\hline ACTR5 & 20 & 37394933 & $\mathrm{~T}$ & $\mathrm{G}$ & I & $\mathrm{S}$ & Missense & $\mathrm{S} 3$ & Yes & 0 & rs34733925 \\
\hline$A C V R L 1$ & 12 & 52309919 & A & $\mathrm{T}$ & $\mathrm{E}$ & $\mathrm{V}$ & Missense & $\mathrm{S} 1$ & No & 0 & NA \\
\hline ADAMTS12 & 5 & 33576162 & G & $\mathrm{T}$ & $\mathrm{S}$ & $\mathrm{R}$ & Missense & $\mathrm{S} 1$ & Yes & 2 & NA \\
\hline$A L P K 2$ & 18 & 56149264 & $\mathrm{C}$ & $\mathrm{G}$ & $\mathrm{G}$ & $\mathrm{R}$ & Missense & $\mathrm{S} 3$ & No & 2 & NA \\
\hline$A T G 2 A$ & 11 & 64676833 & $\mathrm{~T}$ & $\mathrm{C}$ & $\mathrm{Y}$ & $\mathrm{C}$ & Missense & $\mathrm{S} 3$ & No & 2 & rs148849835 \\
\hline$A T P 2 C 2$ & 16 & 84495388 & $\mathrm{~T}$ & A & $\mathrm{D}$ & $\mathrm{E}$ & Missense & $\mathrm{S} 1$ & No & 1 & NA \\
\hline$B C O R$ & $\mathrm{X}$ & 39933872 & $\mathrm{G}$ & A & $\mathrm{R}$ & $\mathrm{C}$ & Missense & $\mathrm{S} 2$ & No & 1 & NA \\
\hline C9orf40 & 9 & 77563010 & $\mathrm{G}$ & $\mathrm{A}$ & $\mathrm{T}$ & I & Missense & $\mathrm{S} 2$ & No & 0 & NA \\
\hline$C A T$ & 11 & 34482880 & G & $\mathrm{T}$ & $\mathrm{R}$ & $\mathrm{L}$ & Missense & $\mathrm{S} 1$ & No & 0 & rs140071186 \\
\hline$C D 5 L$ & 1 & 157805636 & $\mathrm{G}$ & $\mathrm{T}$ & A & $\mathrm{E}$ & Missense & $\mathrm{S} 3$ & No & 2 & NA \\
\hline$C D C A 2$ & 8 & 25319663 & $\mathrm{C}$ & A & A & $\mathrm{D}$ & Missense & $\mathrm{S} 2$ & No & 0 & NA \\
\hline CDHR2 & 5 & 176017571 & AGGAGA & . & QES & $\mathrm{R}$ & Deletion & $\mathrm{S} 2$ & Yes & 0 & NA \\
\hline CDHR2 & 5 & 176017568 & $\mathrm{C}$ & $\mathrm{CT}$ & - & - & Frameshift & $\mathrm{S} 2$ & & & NA \\
\hline CNTN2 & 1 & 205034321 & $\mathrm{C}$ & $\mathrm{A}$ & $\mathrm{F}$ & $\mathrm{L}$ & Missense & $\mathrm{S} 3$ & No & 2 & NA \\
\hline CNTNAP3B & 9 & 43849812 & $\mathrm{~T}$ & G & $\mathrm{C}$ & G & Missense & $\mathrm{S} 1$ & No & 2 & rs3864761 \\
\hline COL22A1 & 8 & 139825238 & A & $\mathrm{T}$ & $\mathrm{Y}$ & $\mathrm{N}$ & Missense & $\mathrm{S} 3$ & No & 4 & NA \\
\hline CTNNB1 & 3 & 41266125 & $\mathrm{C}$ & $\mathrm{T}$ & $\mathrm{T}$ & I & Missense & $\mathrm{S} 3$ & Yes & 16 & rs121913413 \\
\hline CUL9 & 6 & 43152422 & $\mathrm{G}$ & $\mathrm{T}$ & $\mathrm{R}$ & M & Missense & $\mathrm{S} 1$ & Yes & 4 & NA \\
\hline DPP10 & 2 & 116548913 & $\mathrm{~T}$ & $\mathrm{~A}$ & $\mathrm{Y}$ & $\mathrm{N}$ & Missense & $\mathrm{S} 1$ & Yes & 2 & NA \\
\hline EXD1 & 15 & 41507990 & $\mathrm{G}$ & A & Q & $*$ & Nonsense & S3 & Yes & 0 & NA \\
\hline FAM193A & 4 & 2673948 & A & G & $\mathrm{H}$ & $\mathrm{R}$ & Missense & S3 & No & 4 & NA \\
\hline FAM196B & 5 & 169309669 & $\mathrm{G}$ & A & $\mathrm{L}$ & $\mathrm{F}$ & Missense & $\mathrm{S} 3$ & No & 0 & NA \\
\hline$F L N A$ & $X$ & 153594965 & $\mathrm{C}$ & A & $\mathrm{V}$ & $\mathrm{F}$ & Missense & $\mathrm{S} 3$ & No & 1 & NA \\
\hline GPR125 & 4 & 22390134 & $\mathrm{~T}$ & A & $\mathrm{R}$ & $*$ & Nonsense & $\mathrm{S} 1$ & No & 1 & NA \\
\hline$H A D H A$ & 2 & 26426943 & $\mathrm{~T}$ & G & Q & $\mathrm{P}$ & Missense & $\mathrm{S} 3$ & No & 1 & NA \\
\hline HAPLN1 & 5 & 82940402 & A & $\mathrm{T}$ & $\mathrm{D}$ & $\mathrm{E}$ & Missense & $\mathrm{S} 1$ & Yes & 1 & NA \\
\hline$H L A-D R B 5$ & 6 & 32489813 & G & $\mathrm{C}$ & $\mathrm{T}$ & $\mathrm{R}$ & Missense & S3 & No & 5 & rs79606458 \\
\hline$H N R N P H 1$ & 5 & 179046361 & $\mathrm{C}$ & A & $\mathrm{G}$ & W & Missense & $\mathrm{S} 1$ & No & 1 & NA \\
\hline$H R N R$ & 1 & 152188109 & $\mathrm{~T}$ & A & Q & $\mathrm{L}$ & Missense & $\mathrm{S} 2$ & Yes & 14 & rs61814940 \\
\hline$H S P H 1$ & 13 & 31724120 & $\mathrm{C}$ & $\mathrm{T}$ & $\mathrm{E}$ & $\mathrm{K}$ & Missense & $\mathrm{S} 2$ & No & 1 & NA \\
\hline КАТбА & 8 & 41791810 & $\mathrm{G}$ & A & Q & $*$ & Nonsense & S3 & No & 2 & NA \\
\hline KIAA1257 & 3 & 128706628 & $\mathrm{C}$ & $\mathrm{T}$ & W & $*$ & Nonsense & $\mathrm{S} 2$ & No & 0 & NA \\
\hline$K L F 5$ & 13 & 73636078 & G & $\mathrm{T}$ & $\mathrm{R}$ & $\mathrm{L}$ & Missense & $\mathrm{S} 1$ & No & 0 & NA \\
\hline KRT32 & 17 & 39619088 & $\mathrm{~T}$ & $\mathrm{C}$ & $\mathrm{D}$ & G & Missense & S3 & No & 1 & NA \\
\hline LILRA5 & 19 & 54823629 & $\mathrm{C}$ & G & G & $\mathrm{R}$ & Missense & $\mathrm{S} 1$ & No & 1 & NA \\
\hline$M A C C 1$ & 7 & 20193850 & G & A & $\mathrm{P}$ & $\mathrm{L}$ & Missense & S3 & No & 3 & NA \\
\hline MAP $3 K 12$ & 12 & 53876968 & $\mathrm{~T}$ & G & $\mathrm{D}$ & A & Missense & S3 & Yes & 2 & NA \\
\hline MAP3K4 & 6 & 161470088 & $\mathrm{G}$ & A & $\mathrm{E}$ & $\mathrm{K}$ & Missense & S3 & No & 1 & NA \\
\hline MESPI & 15 & 90294304 & $\mathrm{C}$ & $\mathrm{CG}$ & - & - & Frameshift & $\mathrm{S} 2$ & No & 0 & NA \\
\hline MLL3 & 7 & 151945225 & $\mathrm{~T}$ & $\mathrm{C}$ & $\mathrm{E}$ & $\mathrm{G}$ & Missense & $\mathrm{S} 2$ & Yes & 23 & rs77957001 \\
\hline $\mathrm{MROH} 2 \mathrm{~B}$ & 5 & 41061715 & $\mathrm{C}$ & $\mathrm{T}$ & $\mathrm{W}$ & $*$ & Nonsense & S3 & No & 0 & rs1023840 \\
\hline$N A C A D$ & 7 & 45124694 & A & $\mathrm{C}$ & $\mathrm{L}$ & $\mathrm{R}$ & Missense & $\mathrm{S} 3$ & No & 1 & NA \\
\hline$N E B L$ & 10 & 21074726 & $\mathrm{~T}$ & $\mathrm{C}$ & $\mathrm{T}$ & A & Missense & $\mathrm{S} 1$ & No & 2 & NA \\
\hline NPAT & 11 & 108056150 & G & $\mathrm{C}$ & $\mathrm{N}$ & $\mathrm{K}$ & Missense & S3 & No & 0 & NA \\
\hline NVL & 1 & 224455814 & $\mathrm{C}$ & A & $\mathrm{V}$ & $\mathrm{L}$ & Missense & S3 & No & 1 & NA \\
\hline OR13C2 & 9 & 107367609 & $\mathrm{C}$ & A & Q & $\mathrm{H}$ & Missense & $\mathrm{S} 1$ & No & 2 & NA \\
\hline ORIII & 19 & 15198054 & $\mathrm{~T}$ & A & $\mathrm{Y}$ & $\mathrm{N}$ & Missense & $\mathrm{S} 2$ & No & 0 & NA \\
\hline$O R 2 D 3$ & 11 & 6942894 & $\mathrm{~T}$ & $\mathrm{C}$ & $\mathrm{V}$ & A & Missense & $\mathrm{S} 3$ & No & 0 & NA \\
\hline $\mathrm{OR} 2 \mathrm{H} 2$ & 6 & 29556464 & $\mathrm{~T}$ & A & $\mathrm{L}$ & $\mathrm{H}$ & Missense & $\mathrm{S} 1$ & No & 3 & NA \\
\hline PARP4 & 13 & 25051949 & $\mathrm{~T}$ & $\mathrm{C}$ & $\mathrm{Y}$ & $\mathrm{C}$ & Missense & $\mathrm{S} 1$ & No & 9 & NA \\
\hline РCDHA12 & 5 & 140255941 & $\mathrm{~T}$ & $\mathrm{C}$ & I & $\mathrm{T}$ & Missense & S3 & Yes & 0 & NA \\
\hline
\end{tabular}


Table III. Continued.

\begin{tabular}{|c|c|c|c|c|c|c|c|c|c|c|c|}
\hline Gene & $\mathrm{Chr}$ & Position & Ref & Alter & Ref_aa & Alter_aa & Type & Sample & COSMIC & Num in $88^{a}$ & dbSNP \\
\hline РCDHB12 & 5 & 140588823 & A & $\mathrm{T}$ & Q & $\mathrm{L}$ & Missense & S1 & No & 0 & rs199513227 \\
\hline PHLDB1 & 11 & 118527435 & $\mathrm{C}$ & $\mathrm{T}$ & $\mathrm{R}$ & W & Missense & S3 & Yes & 1 & NA \\
\hline PLA2G4C & 19 & 48601455 & G & A & $\mathrm{P}$ & $\mathrm{L}$ & Missense & S2 & No & 0 & NA \\
\hline PLEK & 2 & 68613658 & $\mathrm{~T}$ & G & V & G & Missense & S1 & No & 0 & NA \\
\hline$P P P 1 R 13 B$ & 14 & 104224075 & C & A & $\mathrm{R}$ & $\mathrm{L}$ & Missense & S1 & No & 1 & NA \\
\hline PRAMI & 19 & 8555622 & $\mathrm{C}$ & A & V & $\mathrm{F}$ & Missense & S2 & No & 0 & NA \\
\hline$P R P H$ & 12 & 49690017 & $\mathrm{G}$ & A & $\mathrm{R}$ & $\mathrm{H}$ & Missense & S3 & No & 1 & NA \\
\hline$R A R G$ & 12 & 53606940 & $\mathrm{C}$ & $\mathrm{T}$ & $\mathrm{R}$ & Q & Missense & S2 & No & 0 & NA \\
\hline$R N P E P$ & 1 & 201970804 & C & A & $\mathrm{F}$ & $\mathrm{L}$ & Missense & S3 & No & 0 & NA \\
\hline SEMA3F & 3 & 50225285 & $\mathrm{C}$ & $\mathrm{T}$ & $\mathrm{R}$ & W & Missense & S3 & No & 0 & NA \\
\hline SEMA7A & 15 & 74707184 & $\mathrm{C}$ & $\mathrm{G}$ & $\mathrm{G}$ & $\mathrm{R}$ & Missense & S3 & No & 0 & NA \\
\hline SIGLEC7 & 19 & 51645658 & $\mathrm{G}$ & $\mathrm{T}$ & W & $\mathrm{L}$ & Missense & S3 & No & 2 & NA \\
\hline$S K I V 2 L 2$ & 5 & 54640368 & A & $\mathrm{T}$ & $\mathrm{T}$ & $\mathrm{S}$ & Missense & S1 & No & 0 & NA \\
\hline$S N C G$ & 10 & 88719421 & C & A & $\mathrm{S}$ & $\mathrm{R}$ & Missense & S3 & No & 0 & NA \\
\hline SORL1 & 11 & 121429524 & C & A & $\mathrm{P}$ & $\mathrm{H}$ & Missense & S2 & Yes & 2 & NA \\
\hline TAMM41 & 3 & 11885549 & $\mathrm{~T}$ & $\mathrm{C}$ & $\mathrm{Y}$ & $\mathrm{C}$ & Missense & S3 & No & 0 & rs 149208464 \\
\hline$T B L 3$ & 16 & 2028215 & $\mathrm{C}$ & $\mathrm{T}$ & Q & $*$ & Nonsense & S3 & No & 0 & NA \\
\hline TNKS2 & 10 & 93579726 & A & $\mathrm{T}$ & $\mathrm{N}$ & Y & Missense & S1 & No & 0 & NA \\
\hline$T N N$ & 1 & 175048774 & $\mathrm{G}$ & A & $\mathrm{G}$ & $\mathrm{S}$ & Missense & S2 & Yes & 1 & NA \\
\hline TP53 & 17 & 7577534 & $\mathrm{C}$ & A & $\mathrm{R}$ & $\mathrm{S}$ & Missense & $\mathrm{S} 1 ; \mathrm{S} 3$ & Yes & 34 & rs28934571 \\
\hline TRAPPC8 & 18 & 29444630 & C & A & $\mathrm{R}$ & $\mathrm{L}$ & Missense & $\mathrm{S} 1$ & Yes & 0 & NA \\
\hline \multirow[t]{2}{*}{$T T N$} & 2 & 179402119 & A & $\mathrm{T}$ & $\mathrm{L}$ & $\mathrm{H}$ & Missense & S2 & Yes & 26 & NA \\
\hline & 2 & 179581852 & $\mathrm{C}$ & $\mathrm{CT}$ & - & - & Frameshift & S3 & & & NA \\
\hline$U N C 13 C$ & 15 & 54793167 & A & $\mathrm{C}$ & $\mathrm{R}$ & S & Missense & S3 & No & 4 & NA \\
\hline ZССНC11 & 1 & 52961155 & $\mathrm{~T}$ & $\mathrm{G}$ & $\mathrm{T}$ & $\mathrm{P}$ & Missense & S3 & No & 0 & NA \\
\hline ZFYVE16 & 5 & 79768637 & G & A & $\mathrm{R}$ & Q & Missense & S3 & Yes & 0 & NA \\
\hline ZNF605 & 12 & 133503218 & $\mathrm{~T}$ & $\mathrm{C}$ & $\mathrm{K}$ & $\mathrm{E}$ & Missense & S1 & No & 1 & NA \\
\hline ZNF717 & 3 & 75786430 & C & $\mathrm{T}$ & $\mathrm{G}$ & $\mathrm{R}$ & Missense & S3 & No & 47 & NA \\
\hline
\end{tabular}

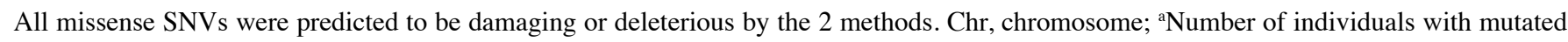
corresponding genes in the $88 \mathrm{HBV}$-related HCC patients; SNVs, single nucleotide variations.

HRNR, CTNNB1, MLL3, TTN and TP53 have previously been reported in the COSMIC database. However, the variants identified in $T T N$ were reported for the first time here.

\section{Discussion}

We performed exome sequencing of HCCs and corresponding normal tissues from 3 Chinese male BCLC stage A HCC patients with chronic $\mathrm{HBV}$ infection to identify key genetic lesions contributing to the initial stage of the disease. Further whole genome sequence analysis in 88 patients at various stages (across early to advanced stage) was also carried out to check the prevalence of the mutated genes.

Eighty protein-altering somatic mutations, including exonic indels, nonsense SNVs and missense SNVs which were predicted to be damaging by 2 function prediction methods were detected and validated in this study. Fifty-nine genes were first reported to mutate in HCC in the present study (Table III).
For the 78 genes with these variants, 47 of them were also mutated at least once in the 88 WGS samples. Among them, 7 genes, ZNF717 and PARP4, HRNR, CTNNB1, MLL3, TTN and TP53 were mutated in at least 9 patients (over 10\%, Fig. 1). HRNR, CTNNB1, MLL3, TTN and TP53 were reported to be related to HCC according to the COSMIC database.

TP53 is a famous tumor suppressor gene. The missense SNV identified on TP53 here was also called R249S, and it is frequently found in $10-61 \%$ of HCC cases $(17,18)$. Consistently, we identified the mutation in sample $\mathrm{S} 1$ and S3 and further WGS analysis also detected this mutation in 10 samples. In HCC, TP53 mutations also vary in different geographic areas, presumably reflecting differences in both etiological agents and host susceptibility factors (19). In some areas, such as sub-Saharan Africa and China, aflatoxin B1 exposure and chronic viral hepatitis are responsible for a very high incidence of HCC (with up to 100/100,000 cases/year), where a high proportion of an R249S point mutation was found (20-22). Furthermore, it was shown that adduction of $\mathrm{AFB}_{1}$ metabolites in the third base of codon 249 in the TP53 
leading to the R249S mutation (23), indicating that this is an early mutational event in hepatocarcinogenesis. Recently, it was found that TP53 with mutation R249S can interact with $\mathrm{HBx}$, which may contribute to cell proliferation and survival of HBx-expressing HCC cells (24). Thus, this mutation may play an important role in the cancer development of HBV-induced HCC patients.

The missense SNV of ZNF717 was detected in sample S3. The mutation was also detected in other WGS samples. Protein-altering variants of ZNF717 were detected in 47 WGS samples at various stages. This suggested that this gene may be related to various stages of the disease. Protein encoded by this gene belongs to the zinc-finger family, which is known to play key roles in regulating expression of genes important for cell growth, proliferation, differentiation and apoptosis $(25,26)$. However, the function of most zinc-finger proteins in tumor occurrence and development is currently unknown. As a zinc-finger protein containing 8 conserved C2H2-type zinc-finger motifs, ZNF717 may function in the transcriptional regulation. Further investigations should be carried out to confirm its roles.

PARP4 was also reported for the first time here. The missense SNV is detected in sample S1. Other proteinaltering mutations of this gene were also detected in 9 other early-stage WGS samples. The protein encoded by this gene is involved in the base excision repair pathway (hsa03410). A previous study showed that inhibition of PARP4 interfered with DNA base excision repair but can sensitize cells to apoptotic stimuli, resulting in increased tumor cell apoptosis in vivo. Interruption of this gene may prevent tumor formation through this mechanism (27). Thus, mutations of this gene at early-stage of the disease may serve as a self-compensation.

Several other newly discovered genes are also noteworthy. For example, the protein encoded by FLNA is an actin-binding protein that crosslinks actin filaments and links actin filaments to membrane glycoprotein. It is involved in several important pathways, such as the MAPK signaling pathway (hsa04010) and proteoglycans in cancer (hsa05205). Although mutation of this gene in HCCs has not previously been reported, comparative proteomics analysis showed that FLNA protein was significantly differentially expressed in HCC cell lines and may influence the metastasis of HCC cells (28). Mutation of this gene was also detected in another early-stage HBV-induced HCC patient of the WGS samples, indicating that interruption of this gene at early stage may contribute to the initial formation of the disease. Moreover, FLNA protein is also involved in the focal adhesion (hsa04510) pathway. Another newly reported gene here, CNTN2, is also related to cell adhesion as it is a member of the cell adhesion molecules pathway. The cell adhesion pathway is important for cancer cell invasion and metastasis. Abnormality of the cell adhesion pathway is considered a characteristic of the advanced stage of cancer. Our findings here thus support the hypothesis that the cancer cells may have acquired the capacity for metastasis at the early stage of development (29). Four genes involved in olfactory transduction including $O R 13 C 2, O R 1 I 1, O R 2 D 3$ and $\mathrm{OR} 2 \mathrm{H} 2$ were also found for the first time in this study to be mutated in HBV-induced HCCs, suggesting these genes warrant further investigation.
In summary, exome sequencing of HCCs and adjacent normal tissues from 3 BCLC stage A HCC patients was carried out to identify key genetic lesions contributing to the initial stage of the disease. Eighty damaging mutations were validated and 59 genes were first reported to be mutated in HBV-related HCCs here. Further WGS analysis showed that mutations in 33 of the 59 genes were also detected in other samples. Variants of 2 newly found genes, ZNF717 and PARP4, were detected in more than $10 \%$ of the WGS samples. Several other genes, such as FLNA and CNTN2, are also noteworthy. Thus, the exome sequencing analysis of 3 BCLC stage A patients provided new insights into the molecular events governing the early step of HBV-induced HCC tumorigenesis.

\section{References}

1. El-Serag HB and Rudolph KL: Hepatocellular carcinoma: epidemiology and molecular carcinogenesis. Gastroenterology 132: 2557-2576, 2007

2. Jemal A, Bray F, Center MM, Ferlay J, Ward E and Forman D: Global cancer statistics. CA Cancer J Clin 61: 69-90, 2011.

3. Perz JF, Armstrong GL, Farrington LA, Hutin YJ and Bell BP: The contributions of hepatitis B virus and hepatitis $C$ virus infections to cirrhosis and primary liver cancer worldwide. J Hepatol 45: 529-538, 2006.

4. Schütte K, Bornschein J and Malfertheiner P: Hepatocellular carcinoma - epidemiological trends and risk factors. Dig Dis 27: 80-92, 2009.

5. Stratton MR: Exploring the genomes of cancer cells: progress and promise. Science 331: 1553-1558, 2011.

6. Stratton MR, Campbell PJ and Futreal PA: The cancer genome. Nature 458: 719-724, 2009.

7. Meyerson M, Gabriel S and Getz G: Advances in understanding cancer genomes through second-generation sequencing. Nat Rev Genet 11: 685-696, 2010.

8. Sung WK, Zheng H, Li S, et al: Genome-wide survey of recurrent HBV integration in hepatocellular carcinoma. Nat Genet 44: 765-769, 2012.

9. Li M, Zhao H, Zhang X, et al: Inactivating mutations of the chromatin remodeling gene ARID2 in hepatocellular carcinoma. Nat Genet 43: 828-829, 2011.

10. Tao Y, Ruan J, Yeh SH, et al: Rapid growth of a hepatocellular carcinoma and the driving mutations revealed by cell-population genetic analysis of whole-genome data. Proc Natl Acad Sci USA 108: 12042-12047, 2011.

11. Totoki Y, Tatsuno K, Yamamoto S, et al: High-resolution characterization of a hepatocellular carcinoma genome. Nat Genet 43: 464-469, 2011.

12. Li H and Durbin R: Fast and accurate long-read alignment with Burrows-Wheeler transform. Bioinformatics 26: 589-595, 2010.

13. Li H,Handsaker B, Wysoker A, et al: The sequence alignment/map format and SAMtools. Bioinformatics 25: 2078-2079, 2009.

14. Koboldt DC, Zhang Q, Larson DE, et al: VarScan 2: somatic mutation and copy number alteration discovery in cancer by exome sequencing. Genome Res 22: 568-576, 2012.

15. Choi Y, Sims GE, Murphy S, Miller JR and Chan AP: Predicting the functional effect of amino acid substitutions and indels. PLoS One 7: e46688, 2012.

16. Ng PC and Henikoff S: SIFT: predicting amino acid changes that affect protein function. Nucleic Acids Res 31: 3812-3814, 2003.

17. Hussain SP, Schwank J, Staib F, Wang XW and Harris CC: TP53 mutations and hepatocellular carcinoma: insights into the etiology and pathogenesis of liver cancer. Oncogene 26: 2166-2176, 2007.

18. Imbeaud S, Ladeiro $\mathrm{Y}$ and Zucman-Rossi J: Identification of novel oncogenes and tumor suppressors in hepatocellular carcinoma. Semin Liver Dis 30: 75-86, 2010.

19. Staib F, Hussain SP, Hofseth LJ, Wang XW and Harris CC: TP53 and liver carcinogenesis. Hum Mutat 21: 201-216, 2003.

20. Kew MC: Synergistic interaction between aflatoxin B1 and hepatitis B virus in hepatocarcinogenesis. Liver Int 23: 405-409, 2003.

21. Parkin DM, Bray F, Ferlay J and Pisani P: Global cancer statistics, 2002. CA Cancer J Clin 55: 74-108, 2005. 
22. Scorsone KA, Zhou YZ, Butel JS and Slagle BL: p53 mutations cluster at codon 249 in hepatitis B virus-positive hepatocellular carcinomas from China. Cancer Res 52: 1635-1638, 1992.

23. Bressac B, Kew M, Wands J and Ozturk M: Selective G to T mutations of p53 gene in hepatocellular carcinoma from southern Africa. Nature 350: 429-431, 1991.

24. Gouas DA, Shi H, Hautefeuille AH, et al: Effects of the TP53 p.R249S mutant on proliferation and clonogenic properties in human hepatocellular carcinoma cell lines: interaction with hepatitis B virus X protein. Carcinogenesis 31: 1475-1482, 2010.

25. Ladomery M and Dellaire G: Multifunctional zinc finger proteins in development and disease. Ann Hum Genet 66: 331-342, 2002.
26. Papavassiliou AG: Transcription factors: structure, function, and implication in malignant growth. Anticancer Res 15: 891-894, 1995.

27. Hans MA, Müller M, Meyer-Ficca M, Bürkle A and Küpper JH: Overexpression of dominant negative PARP interferes with tumor formation of HeLa cells in nude mice: evidence for increased tumor cell apoptosis in vivo. Oncogene 18: 7010-7015, 1999.

28. Ai J, Huang H, Lv X, et al: FLNA and PGK1 are two potential markers for progression in hepatocellular carcinoma. Cell Physiol Biochem 27: 207-216, 2011.

29. Scheel C, Onder T, Karnoub A and Weinberg RA: Adaptation versus selection: the origins of metastatic behavior. Cancer Res 67: 11476-11480, 2007. 